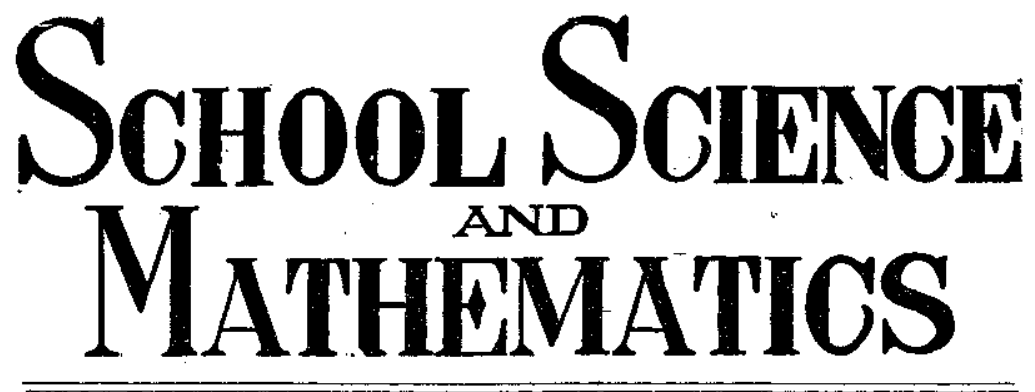

Vol. XX, No. 5 MAy, $1920 \quad$ Whole No. 169

\title{
BIRD STUDY IN THE MISSISSIPPI VALLEY.1
}

By Horace Gunthorp,

Washburn College, Topeka, Kans.

For this discussion I wish to divide the subject into two headings, the first being a statistical study of the membership of the three principal bird societies of the United States, and the second, a discussion of the number of bird courses given in the colleges and universities of this regicn-the Mississippi Valley. At first thought these subjects may appear either not at all or only remotely related to each other, but I hope to make the interrelationship clear as I proceed.

\section{Brrd SocIety Membership.}

The following table of membership in the three principal ornithological societies is compiled from the latest published lists of members, all of which appeared last spring (1919), and includes all classes of members in each case. ${ }^{2}$

\section{Membership in Ornithological Societies.}

Eastern States:

\begin{tabular}{|c|c|}
\hline Laine $(2)$ & \\
\hline New Hampshire. & \\
\hline Vermont (1)... & \\
\hline Massachusetts (23). & \\
\hline Rhode Island & \\
\hline Connecticut (5). & \\
\hline New York (19) & \\
\hline Pennsylvania (7) & \\
\hline New Jersey $(3) \ldots$ & \\
\hline $\begin{array}{l}\text { Delaware } \\
\text { Maryland }\end{array}$ & \\
\hline West Virginia & \\
\hline Washington, D. C. (27) & \\
\hline
\end{tabular}

Southern States

$$
\text { Virginia }
$$

A. O. U. Cooper Wilson Total

'Revised from paper read before The Wilson Ornithological Ciub, at St. Louis, Mo., Dec. $29,1919$.

'American Ornithologists' Union list from The Aut, Vol. 36, pp. XIIT-XLV, April, 1919; Cooper Ornithological Club list from The Condor, Vol. 21, pp. 135-144, May, 1919; Wilson Ornitbological Club list from The Wilson Bulletin, Vol. 31, pD. 29-40, March, 1919. 


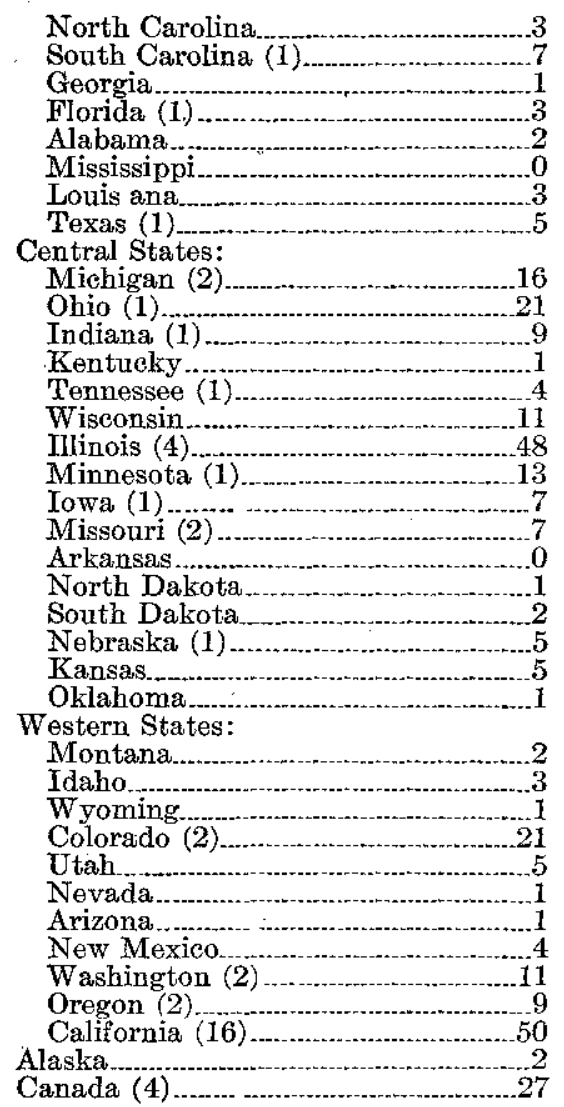

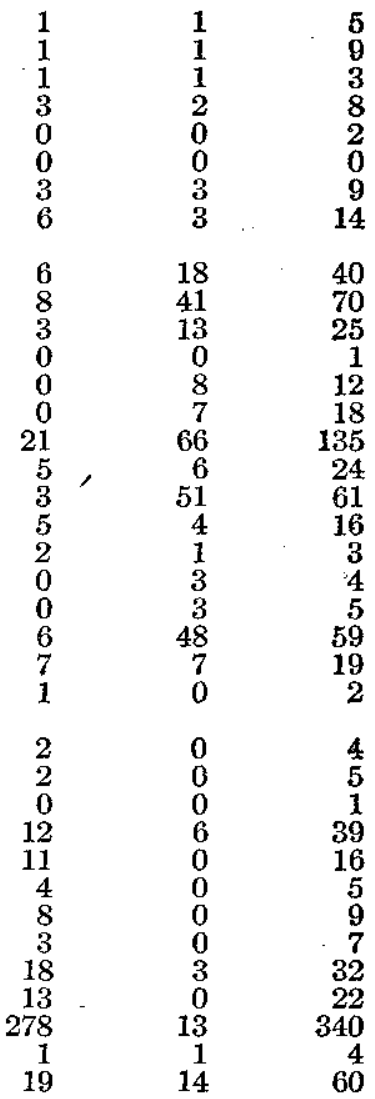

In the Wilson list, under Nebraska, are included forty-seven names of members of The Nebraska Ornithologists' Union, a society affiliated with the Wilson Ornithological Club. There is some duplication of names, as often a single person belongs to all three societies, but it is probably true that such an individual is worth three times as much to ornithology as the person who belongs to only one society. The present membership is undoubtedly somewhat larger than these figures show, as the study of ornithology has been taken up with renewed vigor since the close of the war, and a more or less energetic campaign has been carried on for members in the several societies. To illustrate the increase, I have a letter from Dr. T. S. Palmer, Secretary of the American Ornithologists' Union, in which he states that since the election last November, there are now twelve members in Kansas, whereas the table shows only five. However, even if these figures are somewhat out of date, the main 
facts I wish to bring to your attention will still be illustrated by them, and as they are of equal age for the three societies, comparisons are possible.

It will be noticed at once that the Southern States are especially short of members. This may be due to several reasons, probably the largest one of which is general apathy on the part of the educated classes towards bird problems of the day. Certainly we have had few indications from the lawmaking bodies of the states in question to manifest that they are interested in bird protection, and they must reflect to a large degree the general condition. However, some valuable bird reports have come from Southern States, as those of North and South Carolina. Perhaps lack of members is due to the fact that no serious campaign for them has been carried on. If such is the case it can easily be remedied. The colleges and high schools make natural focal points for starting such a campaign, but those of the South are not as well organized, especially in the sciences, as they are in the North.

Both the East and West have heavy memberships, centered in the former region in Massachusetts and New York, and in the latter, in California. And both of these centers are carrying on active work of a high class.

Turning to our own.territory, the Mississippi Valley, we find some States with a good number enrolled, as for example, Ohio Illinois, Iowa and Nebraska, but most of the remainder are a long way behind where they should be. And one of the strange facts is that we have one of the best territories for bird study on the continent, owing to the fact that we are on the migration route of so many species. Certainly right at home is our field for doing missionary work to convert more people into bird lovers and bird students, and to get them to express their interest by joining a bird society.

The American Ornithologists' Union has three classes of members, the lowest class being Associates, number unlimited, the second class being Members, limited to one hundred, and the highest class being called Fellows, of which there can be no more than fifty. Associates are elected to the higher classes for exceptional research in some branch of ornithology, so it is safe to presume the one hundred fifty names contained in the lists of Fellows and Members of the A. O. U. contain the most imminent bird men in the country. In the above table, the numbers in parentheses directly following the name of the state repre- 
sents the total of Fellows and Members of the A. O. U. who reside therein, according to the published list. If we study this list of one hundred fifty names, we find their totals tally rather closely with the totals in the last column, representing the total memberships in all three societies, with the exception of the District of Columbia, this being due, of course, to the large number of scientists in Washington employed by the Government. They also seem to center around large museums, and this leads to the conclusion that the majority of them gained their standing through systematic work. Such has probably been the case in the past, but during recent years other lines of endeavor are beginning to take the place of systematic study.

It is probable that the close association of imminent ornithologists with the totals of membership in the three societies is due to the fact that when a man is especially interested in a subject he emanates enthusiasm to those around him, and they are much more liable to become interested in the same line of work. The interest of these men would also lead to a more virile campaign for members, and so an endless chain would be started.

The Central States have a total of fourteen names in the list of Fellows and Members of the A. O. U., Illinois leading with four. This is fair, but below what we should have. However, it is in proportion to our total memberships. I think the workers of this region often let outside ornithologists come in and do our good things for us. I know this is true of the North Dakota lake region, and other places. Or perhaps our best men leave us for fresh bird fields.

Courses in Ornithology.

Regarding the number of colleges and universities in the Mississippi Valley which give courses in ornithology, I find there are a total of about one hundred forty schools of this rank having over one hundred college students, and of these, thirty-four give such a course, one other (probably more) offers considerable bird study as part of another course in zoology, and one hundred five give no such work, so far as I am able to learn. In other words, approximately thirty per cent of the institutions give bird courses.

The following table gives in tabular form a few particulars regarding the courses given in the institutions offering ornithology. It is compiled almost entirely from information gained from a questionnaire sent to the teachers giving these courses, 
or to the heads of the biology or zoology departments, when such instructors were unknown. The responses were prompt and full, and I wish to thank those who so kindly cooperated with me in this effort.

\begin{tabular}{|c|c|c|c|c|}
\hline Institution & $\begin{array}{l}\text { Courses } \\
\text { given }\end{array}$ & $\begin{array}{c}\text { Hours of } \\
\text { credit }\end{array}$ & $\begin{array}{l}\text { Semester } \\
\text { fee }\end{array}$ & Laboratory \\
\hline Baldwin-Wallace, 0 & 1 & 2 & $\$ 1.00$ & Yes \\
\hline Carthage, Ill. & 1 & 2 & 3.00 & Yes \\
\hline Central, Mo. & 1 & $2-3$ & None & Yes \\
\hline Coe, la. & 2 & 6 & 5.00 & Yes \\
\hline Doane, Nebr. & 1 & 1 & None & None \\
\hline Drake, Ia. & 1 & 5 & 1.00 & Yes \\
\hline Drury, Mo. & 1 & $2-3$ & 2.00 & For extra hour \\
\hline Earlham, Ind. & $\mathrm{i}$ & 2 & 1.00 & None \\
\hline Eureka, Ill................... & 1 & 3 & None & Yes \\
\hline Fargo, N. Dak. & $I$ & 3 & 2.00 & Yes \\
\hline Hastings, Nebr............ & 1 & 3 & 2.00 & Yes \\
\hline Hillsdale, Mich. & 1 & 2 & 1.00 & $\overline{\mathrm{Yes}}$ \\
\hline Illinois. & 2 & $4-7$ & None & Not in elementary \\
\hline Illinois Wesleyan. & $\overline{2}$ & 4 & 2.50 & Yes \\
\hline Illinois Woman's Col... & $\bar{I}$ & 1 & .50 & None \\
\hline Indiana & 1 & 2 & 1.50 & Yes \\
\hline Iowa & 2 & 6 & None & Yes \\
\hline Iowa Wesleyan. & $\overline{1}$ & 2 & 1.00 & Yes \\
\hline Kansas. & 1 & 3 & 1.50 & Yes \\
\hline Kentucky & I & 3 & None & Yes \\
\hline Knox, Ill. & I & I & 1.00 & Yes \\
\hline McPherson, Kans. & 2 & 8 & 2.50 & Yes \\
\hline Mich. Agricultural Col. & 1 & 5 & 1.00 & Yes \\
\hline Minnesota & 2 & 4 & None & Yes \\
\hline Morningside, Ia.......... & 1 & 4 & 2.00 & Yes \\
\hline Nebraska. & 1 & 1 & 2.00 & Yes \\
\hline Oberlin, Ohio & 3 & $5-6$ & 2.00 & Yes \\
\hline Ohio State. & 1 & 2 & None & Yes \\
\hline Ohio Wesleyan & $\tilde{I}$ & 2 & 1.00 & Yes \\
\hline Washburn, Kans......... & 1 & 2 & 1.00 & None \\
\hline Western Reserve, O.... & 1 & 3 & 5.00 & Yes \\
\hline Wilmington, $\mathrm{Ohio}^{3}$ & 1 & 2 & None & \\
\hline Wiseonsin & i & 2 & 1.50 & Yes \\
\hline Yankton, S. Dak........ & 1 & $\overline{3}$ & Yes & Yes \\
\hline
\end{tabular}

There is considerable variation in the nature of the single elementary course given by most of the schools, some of them making it a popular study with no prerequisites, while in others it is an advanced course with a year of biology or zoology before it. Of one course of the former character, the instructor says: "Perhaps we should call it a bird club rather than a class." From this on the one hand, we pass to the more pretentious classes, and finally to those where a second course in ornithology is given. In most of the schools, the second course, is like the first, general in nature, but more advanced. In Illinois, the elementary course does not have laboratory, but the advanced does. In Minnesota, the first one has laboratory but no field 
work, while the second is the reverse. In Oberlin the first two courses are general, but "The other spring course is entirely devoted to the study of current migration."

The number of semester hour credits given varies from one to five for a single course, and from four to eight for two or three courses. In the case of McPherson College, where eight may be obtained, "This course is by appointment and credit depends on amount and grade of work done."

Fees vary from none to $\$ 5$ per course. The average for those given, not counting the ones where no fee is charged, is $\$ 1.83$. The fee in connection with three or four hour courses should probably be somewhat higher than this, judging from the two following quotations, where the fee is $\$ 2$ : "Should be more to cover expense of skins and mounts injured and destroyed by students." "Fee should be higher, but students usually have to buy a field glass and one or two books, and we have hesitated about raising the fee." Where there is no fee at present, we hear that "We will add a fee next year," and "None this year. Think we should have a fee of at least $\$ 2$." It looks as if the H. C. L. has hit bird courses as well as everything else!

Five of the colleges do not offer laboratory work with their bird courses. In the rest it varies considerably, according to material available and inclination of the instructor. Without exception, field trips are included in every course given. There is a great deal of variation as to how much of the time is put in in this way, but in most of the courses field work forms a substantial and important part. The early weeks of the course seem more likely to be devoted to laboratory and the latter ones to field work. The migration period and weather conditions have an important bearing on the time and proportion of each. Very often we find the statement that the class has either laboratory or field trips every week, the one taking the place of the other.

If the schools giving bird courses listed in the above table are arranged by States, it will be seen that Mlinois and Ohio lead with six, while Iowa is a close third with five. If one refers back to the table of membership in the bird societies, it will be noted these same three States lead the Central group in total members, and in the order named. In fact, this relationship between the number of institutions giving courses in ornithology and the total membership in bird societies continues all down the line with remarkable regularity, as shown in the following table: 


\begin{tabular}{|c|c|c|c|c|c|}
\hline State & Colleges & Members & State & Colleges & lviembers \\
\hline Illinois & 6 & 135 & Minnesota. & 1 & 24 \\
\hline Ohio.. & 6 & 70 & Wisconsin & 1 & 18 \\
\hline Iowa. & 5 & 61 & South Dakota... & $\mathbf{1}$ & 5 \\
\hline Nebraska.. & 3 & 59 & North Dakota.... & 1 & 4 \\
\hline Kansas. & 3 & 19 & Kentueky .............. & 1 & 1 \\
\hline Michigan. & 2 & 40 & Tennessee................... & 0 & 12 \\
\hline Indians & $\overline{2}$ & 25 & Arkansas & 0 & 3 \\
\hline Missouri & 2 & 16 & Oklahoma & 0 & 2 \\
\hline
\end{tabular}

If the sizes of the institutions concerned and the length of time the courses have been given are considered, I am sure the few irregularities in the above table could be accounted for. This parallelism leads one to the conclusion that there is a close relationship between courses in ornithology in our colleges and universities and the prosperity of our bird societies. Most students become interested in and enthusiastic about birds when studying them, and if their attention is called at the proper time to the work of the societies, a considerable proportion will join and keep up their membership. But we must have teachers who believe in bird societies themselves.

In this connection, it is interesting to note that the teachers of these thirty-four bird courses are as a rule not members of a bird society. In the lists of members of the three societies above referred to, we find the names of the instructors giving these courses appearing a total of twenty-four times, distributed as follows: A. O. U., ten; Cooper, five; Wilson, nine. But two persons belong to two societies, and five, to all three. This reduces the number of individuals belonging to twelve, or a little over one-third of the total number. The reason for this lack of interest probably comes under one of the following heads: First, it may be for financial reasons. If this is the case, it would be a good idea to join, and let the school pay the fee from its library fund and place the magazines as received in the library. If the course is worth giving, it is worth providing magazines for. Second, this lack of interest may be due to lack of knowledge of the existence of these societies. In my own case, I discovered it more or less by accident. There are very few mentions in bird literature of these societies and the work they are doing. Persons interested in their growth do not seem to realize the value of publicity. It cannot be done to any great extent through the magazines the societies themselves publish. A third reason is that a good many of the instructors are not interested in the investigation side of ornithology, and as a result they find little to interest them in the literature or magazines 
published by the societies, as these seem too often to run to technical matter of interest to no one except the specialist. The Cooper Club seems to be meeting this situation to a certain extent, and a considerable portion of The Condor is really readable, with numerous pictures. The one other drawing card the societies have is their annual meetings. But it is only once in a while that a person is near enough to the place of meeting to be able to attend one of these, so, for most members, they are few and far between, and this advantage of membership is largely negative. The Wilson Club has wisely become affiliated with the American Association for the Advancement of Science, and as a result their annual meetings are held at the same time and place as the meetings of a large group of other scientific societies. This should add greatly to the attendance and interest in these gatherings, and make them well worth while. The Cooper Club has tried to solve this question by having monthly meetings in centers where there are enough members to warrant them. This combines features of both local and national bird societies, and seems to be working well.

The Mississippi Valley is the special territory of the Wilson Ornithological Club, and this society deserves our special support for this reason, if for no other. There are four classes of members, Honorary, Sustaining, Active, and Associate, and the membership (March, 1919) is 4, 18, 203 and 194 for the four classes respectively. The club publishes The Wilson Bulletin, a quarterly of from forty to fifty pages a number. This is now in its thirty-second volume, and is under the able editorship of Dr. Lynds Jones, of Oberlin. As mentioned above, the annual meetings are in conjunction with the meetings of the A. A. A. S., and for this reason should be comparatively easy to attend, especially for science teachers.

In conclusion, we need more members in our bird societies, and there are two places from which to draw them, either from the ranks of those who are already interested in the subject, or by making more bird lovers from which to draw. To reach persons at present interested in the subject is a problem that is up to the officers and members of the societies. That the surface has hardly been scratched is shown by the large per cent of teachers giving bird courses who are not members of any organization of national scope. This being so, a moments thought will lead one to conclude there must be even a larger per cent of laymen outside the membership rolls. In regard to making more 
bird lovers, from the figures given above, certainly there is no better way than by giving courses on birds in our colleges and universities. A little knowledge in this case does not usually prove to be a dangerous thing, but, on the contrary, serves as leaven for a more intimate knowledge and growing interest as the years go by. And if such students can be interested in a bird society, it will help keep them in touch with the subject for the rest of their lives, and here and there among their number may be found a real-bird student, the kind we must have to keep ornithology on a. level with the other sciences.

\section{PRODUCTION OF CADMIUM IN 1919.}

The output of metallic cadmium in 1919 was 99,939 pounds, compared to 127,164 pounds in 1918 and 207,408 pounds in 1917 , the maximum output in the history of the industry. The production of cadmium sulphide was 31,197 pounds, compared to 51,702 pounds in 1918 . The combined value of metallic cadmium and cadmium sulphide in 1919 was about $\$ 160,000$, compared to $\$ 258,518$ in 1918 and $\$ 376,036$ in 1917 . These figures, computed by C. E. Siebenthal, are made public by the U. S. Geological Survey; Department of the Interior.

Though prices of cadmium were somewhat lower in 1919 than in the three years immediately preceding, the industry closed the year in better condition than in 1918 , for the reason that the consumption practically reached the level established in 1916-17, and this with the docreased production operated to reduce stocks.

\section{LIGHT FOR RETOUCHING.}

An expert in retouching writes very sensibly in The British Journal as follows: "In the days when I did a good deal of retouching I found it best to avoid any arrangement which allowed any light, however diffused, to fall directly on the negative, as it was always very trying to the eyes, and I maintain that retouching ought not to produce eye-strain if the negative is properly illuminated. I have often retouched till long past midnight without getting my eyes tired. The arrangement I have always used, whether the source of light was paraffin-lamp, incandescent gas, electric or daylight, allowed no light to fall directly on the negative, but was all sent upward through the negative by relection from a sheet of white paper, or if the negative was extremely dense a piece of matte sheet-aluninium was used instead.

"Eye-strain in retouching is caused by trying to see every stroke made by the pencil. I believe that it may be almost entirely avoided by working at such a distance that each touch is not seen but only the general effect, working just as an artist does when he 'stipples' in watercolor or minature-painting.

"Many retouching-desks are not sufficiently upright; the slope of the des's should not $\mathrm{ke}$ less than sixty degrees. This will be found more restful and healthy, and will not cause the worker to stoop. This was the angle of the desks used by the mediaeval writers, who spent their lives writing at a time when writing was a fine art. I often wonder that men who spend their days 'pen-pushing' do not use a desk with a steep slope; they would get far less indigestion and have straighter backs." -Photo Eri. 